\title{
Community Perception, Satisfaction and Participation toward Power Plant Development in Southernmost of Thailand
}

\author{
Sarawuth Chesoh (Corresponding author) \\ Pattani Fisheries Research and Development Center, Pattani, Thailand, 94160 \\ Tel: 66-73-468-826 E-mail: chesoh.s@hotmail.com
}

\begin{abstract}
A quantitative-qualitative mixed method was applied to investigate perception, satisfaction and participation of inhabitants toward the power plant development in Thailand. A total of 1000 households and 20 community leader were selected and were taken in-depth interviewed annually from January 2005 to December 2008. The direct affected inhabitant was expected to exceed 6,325 households in the Nathab River vicinity. Most of the respondents indicated that they knew various project development programs and overall satisfactions of respondents range from 83 to $95 \%$. Male, education, social status, family income and asset, ability of accessing information, sense of democracy, public interest awareness, resources dependence for livelihood, caliber of project public relation staff, frequencies of community visiting and public funding were positively and significantly associated with level of project participation. Participation model is required for the clear guidelines in all stages based on (1) freedom, ability and willingness, (2) two-way communication, (3) transparency, and (4) co-management practice.
\end{abstract}

Keywords: Electric Authority of Thailand (EGAT), Mega-project development, Public concerns, Social assessment

\section{Introduction}

Public acceptance has played an important component in power plant development. Thus, public opinion, perception and satisfaction are the often key motivating factor for successful acceptance (Choi and Lee, 1995; Bureekul, 2000; Huang et al, 2009). Moreover, community participation has been promoted worldwide intensively in the fields of rural development and natural resources conservation (Norsworthy, 2000).

Rapid growth in electricity demand in Thailand is a major challenge for electric utilities trying to ensure adequate supply. However, this expanding electricity lacks capacity to meet the twin challenges of supply security and environmental protection (Nakawiro et al, 2008). The Electricity Generating Authority of Thailand (EGAT) has the responsibilities to generate and to transmit electricity for the whole country. EGAT's Chana power plant of $710 \mathrm{MW}$ in southern Songkhla province started commercial operation on July 15, 2008 (EGAT, 2009). This new power plant fuelled with natural gas from the Thai-Malaysian Joint Development Area (JDA) in the Gulf of Thailand has significantly strengthened the power supply system of southernmost provinces. However, this plant must consume the huge amount of water from Nathab River estuary for the mechanic cooling system. Fish larvae and juveniles are not strong enough to maintain in the water flow occurring at cooling water intakes as well as heated water effluents. Therefore, local inhabitants are concerned about the destruction to aquatic life and the ecosystem caused by the power plant cooling systems that could directly affect to their livelihoods (Chesoh et al, 2004). In the past, many power plant development projects in Thailand had been implemented by decision-makers without community consultation or public participation (Chaisomphob and Sa-nguanmanasak, 2004). The conflict of interests over the use and management of natural resources as well as environmental concerns of mega-development projects are currently expressed violently at global level and also in Thai society as well (UNEP, 2009). Meanwhile, positive attitudes towards power plant establishment among community's residents will result in more successful development. Therefore, this study aimed to examine the general local's perception, satisfaction and participation to facilitate successful acceptance and collaborative partnership for both community and the power plant development project authority.

\section{Conceptual framework and scope of the study}

The concept of community perception and satisfaction are often discussed as subjective social indicators in sociological research. Perception is the process of attaining awareness or understanding of sensory information from seeing, hearing, smelling, touching and orienting (Wikipedia, 2009). Satisfaction is the act of pleasure, or the state of being pleased; gratification of desire; contentment in possession and delight; repose of mind resulting from compliance with its desires or demands. Participation refers to a process and not a product and involves various role players or stakeholders who determine how and what services are delivered. Participatory relationships are voluntary and their effectiveness depends on stakeholders being convinced that the process serves their interest (Schübeler, 1996). Thus, the members of the community must be allowed to use their own views and convictions to address the specific conditions and problems prevailing in their community. It is much more than the increasing of income, wealth and the economic growth but must be focused on increasingly human development. Participation needs to be considered in decision-making, implementation and maintenance and evaluating successes and failures (Lane, 1995). Community participation always influences the direction and 
execution of community development projects in contrast to communities merely being consulted and receiving project benefits. Participation if it is to be practices in the true sense of the word should be more than a policy statement (Burkey, 1993). The conditions for creating public participation is to (1) encourage the advantage image of project agent (2) provide the information to the people from the preparation phase of the project and (3) promote participation in every step of the project to make sense of belonging by working as a partnership (Bureekul, 2000).

The EGAT's Chana power plant is located in Chana district of Songkhla province where situated about $1000 \mathrm{~km}$ away from Bangkok. It covers the area of 300 square $\mathrm{km}$. of the Nathab River Basin and located between $7^{\circ} 06^{\prime}$ $28^{\prime \prime} \mathrm{N}$ and $100^{\circ} 42^{\prime} 50^{\prime \prime} \mathrm{E}, 6^{\circ} 53^{\prime} 40^{\prime \prime} \mathrm{N}$ and $100^{\circ} 38^{\prime} \mathrm{E}$. The Nathab River originates from several streams in Thailand-Malaysia border region. The river is $26.5 \mathrm{~km}$. in length and flows into the Gulf of Thailand that serves as water supply for 65,000 inhabitants in the basin. Land use along the river banks consists of forestry, agriculture, rubber plantation, fisheries, community settlement, factories, tourism and mining. The Nathab River Basin has played two important roles; first, it serves as a multi-functional ecosystem with a high biodiversity. Second, it contains renewable resources that serve as a food supply and income source of the people living in its vicinity.

This study is based on the assumption that all stakeholders completely comprise a freedom, ability and willingness to participate in every step of project procedures. Individual characteristics (gender, education, social status, family income and asset, accessing information, sense of democracy, awareness of public interest, satisfaction of development program and degree of resources dependence) and caliber of project staff (frequencies of community visiting and grant support) for community perception and participation of this project were investigated.

\section{Materials and Methods}

A cross-sectional survey and quantitative-qualitative mixed methods approach (see details and related examples in Reichardt and Cook, 1979; Creswell, 2003) had been conducted from January 2005 to December 2008. Structural questionnaires were used as informant interviews. We selected 1,000 households and 20 community leaders of 20 villages around the project site and were taken in-depth interview annually. Annual focus groups discussion comprised of 20 participants of community leaders, local scholars and activists together with informal small group discussion were employed in acquiring in-depth information for analysis and finding confirmation (see details in Kruger, 1994). In addition, monthly coffee shop citizen dialogs, and consultative group meeting, were also included for data collection (see details in Maxwell et al, 2002). Power plant construction schedule, mitigation measures of environmental impacts and other relevant documents were reviewed. Descriptive statistics were calculated such as percent and frequency for categorical variables and mean with standard deviation or median with range for continuous variables. Pearson's correlation was used to investigate the correlation between the variables. Linear regression was used to identify the association between outcome and predictors.

\section{Results}

\subsection{General socio-economic of community inhabitant performance}

Of the (total) 1,020 respondents, $79 \%$ of informants were male with average $51.75 \pm 17.3$ years of age. The moderate number of member in households was 5(2-11). Most of the respondents $(85 \%)$ were Muslim. About $64 \%$ had a primary educational level followed by higher education $(28.2 \%)$ and illiterate $(8 \%)$. The most common occupations of respondents were working (laborer) in fishery sector (59.8\%), plantation and livestock (33.5\%), local traders (4.7\%), company officers $(1.2 \%)$ and government sector $(0.8 \%)$. Almost $45 \%$ of informants showed the estimated monthly income, each household could earn about 180-270 US\$, 35\% was about $90-180$ US\$, $12 \%$ was greater than 270 US\$, and $8 \%$ was less than 90 US\$ per capita. In contrast, over $43 \%$ of informants presented the estimated monthly household expenditure about $90-180$ US\$, about $30 \%$ was $180-270$ US\$, and 16\% was 270-360 US\$. More than half of respondents (51\%) had a debt. Among them, , $35 \%$ got loan from the relatives and $65 \%$ got loan from commercial bank, local saving cooperation and village funds. Almost $67 \%$ of respondents have been settled in their community for more than 25 years and $83 \%$ were the ethnic origin resident. Only $17 \%$ were emigrated from the other regions of southern Thailand.

\subsection{Community infrastructure and environmental health care survey}

About $97 \%$ of respondents indicated that they have been admitted at Chana community hospital when they got sick or illness. Almost all (99\%) of respondents have access to public electricity and most of $12 \%$ located out of public pipe water service area. Almost $67 \%$ of respondents drink the water from public pipe water, followed by drinking water bottle (32\%), private shallow well (24\%) and the rainfall water $(13 \%)$. About $31 \%$ of respondents reported that they had suffered of drinking water contamination while $26 \%$ of those have suffered of daily utilized water. About $89 \%$ of respondents indicated that there is no problem of communication. Similarly $93 \%$ of those stated that they burn daily garbage and household waste for keeping the community clean. 


\subsection{Community perception and satisfaction on Chana power plant development programs Information perception}

Most of respondents (97\%) knew about various project development programs around the power plant area; over $79 \%$ of those got information from neighbors, followed by community leaders and project public relation documents. A frequency of message receiving found that about $51 \%$ was monthly, $15 \%$ was weekly and $34 \%$ of respondents stated that they received information directly from power plant officers.

\section{Opinion and satisfaction on development programs}

- Over $86 \%$ of respondents were satisfied on medical health care mobile unit of the project.

- Over $83 \%$ of respondents were satisfied on implementation of local organization base on the budget supporting of the project.

- About $91 \%$ of respondents were satisfied on fish and shrimp releasing program into the river together with fisheries promotion.

- About $87 \%$ of respondents were satisfied on educational grant for being demonstration school improvement.

- Over $95 \%$ of respondents were satisfied on mangrove rehabilitation and conservation program.

- About $88 \%$ of respondents were satisfied on complain and public hearing box setting and access the project information.

- Over $85 \%$ of respondents were satisfied on community participation and being the power plant operating audit committee.

Overall satisfaction of respondents on various community development programs were between 83 to $95 \%$. Majority of the respondents $(76 \%)$ reported that the power plant provide the benefit to nearby communities including increasing the modernization (80\%), supporting stability of electricity supply for southernmost provinces of Thailand (35\%) and facilitating local labor market (47\%). However, $13 \%$ of respondents deeply reflected that the power plant was useless because local inhabitants were unable to participate with the project, and the others stated that there was not enough information of the project development.

\subsection{Factors affecting community participation}

The results indicated that degree of community participation depend on characteristics of household leader and calibers of EGAT's public relation staff. For community side showed that the private personality of household leader; gender, education, social status, family income and asset, ability of accessing information, sense of democracy, public interest awareness and degree of resources dependence for the household livelihood were statistically significant $(\mathrm{p}<0.05)$ related with the project participation. However, there were no significant differences in location and distance within 10 kilometer far from the power plant with community participation $(\mathrm{p}>0.05)$. Moreover, the calibers of project public relation staff, frequencies of community visiting, public activity funding were statistically significant related to community participation $(\mathrm{p}<0.05)$.

\section{Discussion and Conclusion}

\subsection{Community Perception and Satisfaction}

It was seen that mostly (75\%) of local inhabitants were able to perceive and access the information and agree with the project establishment because of increasing electricity demand and were satisfied between 83 to $95 \%$ toward the community development programs of the project. However, one fourth of respondents $(25 \%)$ showed inaccessible, lack of information and disagree with the project development. This minority did not trust in project construction process, technological risk and uncertainty of policy implementation. Most of household leaders were worried about the environmental impacts through harmful aquatic organism. Thermal diffusion and sedimentation from project construction resulting fish habitats and water quality deterioration may cause long-term adverse effects on their livelihood.

In fact, flash flood and converting of flow direction caused by project diversion structures were concerned issues. Actually, conflicts of water use among upstream and downstream inhabitants always take place as well as the conflict among fishermen versus riverside tour entrepreneur. Many informants have expressed different opinions with regards to problems associated with the development projects; some replied that it is political issues; some replied it is a technical issues or economic interest issues and some were nimbly. These problems result from a deficiency of institutions that could enable more effective use of shared resources (Odada, 2004). This complex challenge can be divided into three factors or areas, water and livelihoods; watershed hydrology; and social organization. All factors were overlap but the currently management processes are disharmonizing. According to results, mangrove rehabilitation and fish and shrimp enhancement program were the favorite activities of the locals. These programs should be expanded into new area and increasing budget implementation. In addition, it is necessary to encourage the local specialist to participate in power plant advisory committee and increasing their roles more than those of government officers. 


\subsection{Factors affecting community participation}

The effectiveness of community participation is strongly and positively influenced by the competency of household leader and project public relation staff. Male, higher education, higher social status, higher family income and asset, higher ability of accessing information, higher sense of democracy, higher public interest awareness and higher degree of resources dependence for livelihood were statistically significant $(\mathrm{p}<0.05)$ related with the project participation that enhancing collaboration and reducing argument. In addition, the calibers of project public relation staff, frequencies of community visiting, public activity funding were statistically significant related to community participation $(p<0.05)$. These findings re-enforced that individual and economic security variables were major factors affecting community participation for benefit to further development, and prove to be a valuable tool for evaluating the design and effectiveness of power plant development programs. These findings were consistent with the reports of Ur-Rehman and Chisholm (2007) and Fathom et al (2008) that study about local participation in the natural resource management activities. According to positive and significant correlation between demographic and socioeconomic levels of informants on participation in power plant development, authority should support community development fund and facilitate necessary conditions (job for locals) to establish power plant project.

\subsection{Prototyping model of community participation}

Conditions for achieving community participation of inhabitants who live in the affected project area are (1) create the positive or advantage goodwill of the project to the public especially the environmental conservation and public health (2) establish the confidence or reliance of the project by providing the up to date information to the public continuing from the preparation phase of the project (3) encourage community participation in every step transparency, concentrate public relation and mutual benefit and practices in the true sense of the word and (4) Village funding support such as the public extension and training program including private donation for healing victim's families after disasters, otherwise employment of local people for working in project site. Many people feel that EGAT is organized in centralized structure, the development projects usually are led by business interest. They create burden on consumers and resulting negative social and environmental impact. In addition, influence from mass media affects on attitudes and feelings of the local inhabitants may improve or worsen the situation. A proven method for achieving community participation is to work through individuals who are able to bring people together and promote action. Therefore, the project must ensure that the public relation staffs are professional.

The EGAT's Chana power plant is a true pioneer prototype power project which has integrated a full public participation process in every stage of the project development to ensure fair and sustained benefits for the local community (EGAT, 2009). Local environmental network has been established under the direction of the Environmental Inspection Group for the power plant. The quality of Nathab River, the most important water resources of the locality, is a major concern to the local communities whose livelihood depends significantly on the canal. EGAT and the Nathab River Water Quality Monitoring Network have jointly undertaken several activities to strengthen community capacity in environmental conservation of the river. These activities include:

1) Providing education and knowledge about the ecological system of Nathab River to committee's members and local people's representatives

2) Organizing workshops to demonstrate the use of environmental monitoring equipment and tools in conducting water quality and aquatic ecological resources sampling and analysis. Technical experts from Prince of Songkla University, Pattani Campus have successfully facilitated the workshops.

3) Full participation by the local communities in the vicinity of Chana power plant in the monitoring of water quality, air quality and noise measurement during the commissioning test of the power plant.

By actively participating in these activities, the local communities had better understand on the operation of Chana power plant and its environmental and social responsibility. The local people are now able to monitor the water quality of Nathab River on a continuous basis, using on-site testing kits and visual observations. A practical participation for environmental surveillance has successfully been established in project area. However, the real-time automatic water quality measurement system is necessary placing at critical location in Nathab River mainstream. Beside this, the glass-tube thermometer and chlorine test kit to the fish cage farmers are proper to hand out for roughly water quality measure. It is necessary to promote the local fishing specialists to participate and to enhance their roles in power plant advisory committee. Lack of transparency and participation from local community and stakeholders in the early stage of the project had led to conflicts and protests. Empower the local people to have more power in decision making processes in order to meet the real needs. In addition, emphasize on the public relation staffs to provide widespread information in every channels are strongly recommended. All community stakeholders should be a joint committee in every step of project procedures; beginning at the first step of environmental impact assessment study; planning for land purchasing and project lay out; under construction stage; operation stage and monitoring phase base on freedom, ability and willingness to participate, public relation, citizen dialogue and co-management practice are required. 


\section{References}

Bureekul, T. (2000). Public participation in Environmental management in Thailand. Center for the study of Thai politics and democracy, King Prajadhipok's Institute, Thailand. 67 p.

Burkey S. (1993). People first: A guide to self-reliant participatory rural development, Zed Books Ltd. 244 p.

Chaisomphob, T. and Sa-nguanmanasak, J. (2004). Role of public participation in planning power plant projects in Thailand. Thamasat International Journal of Science and Technology, 9(1): 67-73.

Chesoh, S., Luangtuwapraneet, C., Ruangchuay, R. et a. (2004). Environmental impacts assessment of aquatic ecosystem and fisheries resources utilization of Nathab canal before Songkhla thermal power plant construction. In proceeding of annual fisheries seminar at Department of Fisheries of Thailand during 25-27 July 2006. 77-94.

Choi, S, Y. and Lee, W. B. (1995). Analysis on the perception of nuclear power plant and the preference of its policy alternatives for public acceptance. Journal of the Korean Nuclear Society, 27(1), 33-43.

Creswell, W. J. (2003). Research design: qualitative, quantitative, and mixed method approaches. SAGE, 246 p.

EGAT. (2009) Annual report $2008 . \quad$ Available at, http://pr.egat.co.th/AnnualReport/annual2008/annual08_eng/index_eng.html, Accessed on 30 November 2009

Faham, E., Rezvanfar, A. and Shamekhi, T. (2008). Analysis of socio-economic factors influencing forest dwellers' participation in reforestation and development of forest areas (The case study of West Mazandaran, Iran). American Journal of Agricultural and Biological Sciences 3 (1): 438-443.

Huang, L., Bi, J., Zhang, B., Li, F. and Qu, C. (2009). Perception of people for the risk of Tianwan nuclear power plant. Journal of Frontiers of Environmental Science \& Engineering in China. Higher Education Press, co-published with Springer-Verlag GmbH, 10.1007/s11783-009-0151-z. Friday, November 13, 2009.

Kruger, R.A. (1994). Focus groups: a practical guide for applied research, 2d ed. Thousand Oaks, CA: Sage Publications. 254 p.

Lane, J. (1995). Non-governmental organizations and participatory development: The concept in theory versus the concept in practice. In N. Nelson, \& S. Wright (Eds.), Power and participatory development: Theory and practice (pp. 181-191). London: Intermediate Technology Publications.

Maxwell, J. Jackson, K. and Legowski B. (2002). Report on citizens' dialogue on the future of health care in Canada. Commission on the future of health care in Canada. $124 \mathrm{p}$.

Nakawiro, T., Bhattacharyya, C. S., and Limmeech, B. (2008). Expanding electricity capacity in Thailand to meet the twin challenges of supply security and environmental protection. Journal of Energy Policy, 36, 22652278 .

Norsworthy, L. A. (2000). Rural development, natural resources and the environment: lessons of experience in Eastern Europe and central Asia. World Bank. 136 p.

Odada, O. Eric. (2004). Enabling environment for effective implementation of water management for food and ecosystems, and for poverty alleviation and sustainable development. Report of the African pre-conference on water for food and ecosystems-Addis Ababa, 4-6 November 2004. Annex C-3: Theme 3 An enabling environment. Available at, http://www.fao.org/ag/wfe2005/docs/annex_c3.pdf. Accessed on 30 November 2009.

Reichardt, C. S. and Cook, T. D. (1979). Beyond qualitative versus quantitative methods. In: Cook, T.D. and Reichardt, C.S. Editors, 1979. Qualitative and Quantitative Methods in Evaluation Research Sage, Beverly Hill, CA, pp. 7-32.

Schübeler, P. (1996). Participation and partnership in urban infrastructure management, World Bank, Washington. $101 \mathrm{p}$.

United Nations Environment Programme (UNEP). (2009). From Conflict to peace building; The role of natural resources and the environment. Policy Paper No. 1. $44 \mathrm{p}$.

Ur-Rehman, M. and Chisholm, M. (2007). Analysis management activities in district Abbottabad, NWFP, Pakistan: A Multivariate factors affecting households' participation in the natural resource. Journal of Asian and African Studies 42(6), 495-516.

Wikipedia. (2009). Perception. Available at, http://en.wikipedia.org/wiki/Perception. Accessed on 30 November 2009. 